\title{
Gas: government and market
}

\section{N. van Hulst}

Director-General Energy, Ministry of Economic Affairs

As minister Jorritsma mentioned in her speech this morning, gas is a major source of prosperity for The Netherlands up to this very day.

A unique form of collaboration between government and industry assured this prosperity. What future can be foreseen for this collaboration, now liberalization and market mechanisms are the key words in the European energy scene?

The Netherlands are convinced of the benefits of liberalization, ordaining, however, a wise transition scenario,. The relationship between Government and industry will change. On the one hand, the Government will maintain its special interest because of the gas revenues. On the other hand, Government involvement will be reduced.

The Government wishes to ensure, that the energy companies can continue their excellent work in a liberalized market, in a responsible way. That is the reason for introducing a new Mining Act: to integrate and update the current multitude of regulations; to introduce regulations governing the detrimental ef- fects of soil movements; to formulate regulations for gas storage and the removal of platforms. A new contribution system will be introduced, easing the financial burden for some mining companies and in any case simplifying it for the entire industry.

The new Gas Act is the direct result of the EC Gas Directive, which the Dutch helped formulate. The focus will shift to a demand-oriented structure. Competition between gas suppliers will increase, shifting the emphasis to the "additional services" of the various companies.

Step-wise opening up of the market, for the time being distribution companies will be obliged to keep supplying their established customers. A system of negotiated access to the gas pipeline networks has been chosen. The Netherlands Competition Authority will play a key part as supervising authority.

The gas price for industry will be cut, maybe even for private consumers, although many other factors will affect the gas price as well. 